\title{
Cost-effective footwear for leprosy control programmes: a study in rural Ethiopia
}

\author{
GIRMA SEBOKA \& PAUL SAUNDERSON \\ ALERT, P.O. Box 165, Addis Ababa, Ethiopia
}

Accepted for publication 13 February 1996

\begin{abstract}
Summary A randomized, controlled trial of commercially available canvas shoes was carried out in a rural area of Ethiopia. Subjects with deformed and anaesthetic feet, most with ulceration, were given either canvas shoes or plastazote/moulded shoes and followed up for one year. Seventy-five percent of subjects with ulcers who used canvas shoes had no ulcer at the end of the study, while no significant change was noted in the plastazote group. The durability and acceptability of the shoes were also examined. Clients in remote areas who have no access to an orthopaedic workshop, but who have anaesthetic feet, with or without deformity, should have access to canvas shoes with an MCR insole. Two pairs are needed per year at a cost of US\$6.7 per pair.
\end{abstract}

\section{Introduction}

Plantar ulceration is a major complication of leprosy, which can lead to chronic infection, bone destruction, deformity and eventually amputation, often with prolonged periods of hospitalization. ${ }^{1}$

The cause is repeated trauma to a foot rendered anaesthetic by leprosy neuritis, ${ }^{2}$ while deformity may exacerbate the problem by causing an abnormal distribution of pressure during normal activities. ${ }^{3}$

It is well known that immobilization alone, which breaks the cycle of repeated trauma, leads to healing of most simple ulcers; ${ }^{4,5}$ this process may be augmented by simple wound care. ${ }^{1}$ Many programmes, however, find that it is difficult in the long-term to assist people affected by leprosy in keeping themselves ulcer-f ree. ${ }^{6}$ This may be due to lack of knowledge in the care of feet, but is more likely to be due to their socioeconomic status which precludes rest for prolonged or even short periods.

The provision of special footwear can help to overcome this problem by spreading the pressure more evenly over a wider area of the foot, reducing the trauma to specific pressure points. The person can then effect a compromise between normal activity and complete rest, by reduced activity, the use of protective footwear and wound care. ${ }^{7}$ While the provision of footwear should be an integral part of any leprosy control programme, ${ }^{8}$ it may be very difficult for financial and logistic reasons to make this service available in practice, on a continuing basis. ${ }^{9,10}$ 
Many leprosy control programmes have developed, or have access to, orthopaedic workshops which produce a range of special shoes, including plastazote shoes and boots, open MCR sandals and more sophisticated custom-made boots. However, there are major problems with special footwear, including: 6,9

Cosmetic: clients are easily identified as leprosy patients; this means that many do not wear the special shoes much, if at all.

Custom: e.g. shoes may never be worn inside the house (mentioned from Asia).

Occupation: e.g. working in paddy fields (also mentioned from Asia).

Maintenance and repair: most shoes only last 6 months if worn regularly and repairs are difficult to organize efficiently.

Provision in adequate numbers: this is impossible for most programmes, and often only hospitalized patients are served. In other words, the shoes are not used as a preventive measure, until severe damage has already occurred.

Recent studies in China ${ }^{11,12}$ using canvas shoes with an MCR insole showed an impressive record of ulcer healing and ulcer prevention. At ALERT, we have used the Chinese canvas shoes but found them to be of very poor durability.

More recently, the Ethiopian Canvas Shoe Factory has been able to produce a shoe deep enough to take an additional MCR insole (shore $15^{\circ}$, thickness $8 \mathrm{~mm}$ ) and we have started to provide these in our control programme. The major advantages are the high acceptability to clients and the possibility of providing adequate numbers of shoes at short notice.

This study addresses certain important questions regarding the provision of footwear on a routine basis to people affected by leprosy:

1 Given the difficulty in supplying moulded sandals in the required numbers, would the provision of canvas shoes to people with deformed feet give acceptable results?

2 Can the provision of canvas shoes lead to the healing of existing ulceration, and the prevention of further ulceration, in people with anaesthetic feet (and even deformed feet)?

3 How acceptable and durable are the canvas shoes under field conditions?

4 How cost-effective are canvas shoes as compared to other methods of managing plantar ulceration in the long-term?

\section{Methods}

STUDY DESIGN

A prospective, randomized controlled trial was carried out near Sheshemane, Ethiopia from November 1994 to November 1995.

\section{SUBJECTS}

Seventy people affected by leprosy with deformed and anaesthetic feet, who were regularly attending a foot-care clinic, were randomly allocated to receive either canvas shoes or plastazote/moulded sandals; all had been using moulded sandals in the recent past and most had ulcers; verbal consent to take part in the study was obtained. 
Randomization was by day of attendance at the clinic. Subjects were examined at the start and subsequently at 2, 4, 6 and 12 months by one of us (GS), together with one of two local supervisors. The majority were farmers living in and around the village of Kuyera.

Health education had been given in the past to these people, but no additional educational measures were taken during this study.

There were two exclusions from the plastazote group (one was admitted to hospital and the other refused to attend for follow-up). Results are reported for 68 subjects.

\section{OUTCOME MEASURES}

Ulcer size was measured at each visit and the area of ulceration was calculated according to the following formula: $0.785 \times$ length $\times$ width. ${ }^{13,14}$ At all follow-up visits, the shoes were examined for wear and tear and the subjects were asked a series of questions concerning the acceptability of the footwear and how helpful they found the shoes in assisting with their foot care.

COSTS

The cost of providing both types of footwear was also examined in order to provide a cost-effectiveness analysis (CEA). The canvas shoes were sold at the wholesale price to us, namely US $\$ 6.7$ per pair. The true cost of manufacturing the moulded sandals could not be ascertained, but is likely to be more than US\$20 per pair, the materials alone costing US\$12.7 per pair. Distribution costs were not examined.

\section{Results}

\section{SAMPLE CHARACTERISTICS ON ENTRY}

Table 1 shoes the sample characteristics at the start of the study.

\section{AREA OF ULCERATION}

Figures 1 and 2 show the area of ulceration found at the start and at subsequent followup visits, for the plastazote sandal and canvas shoe groups, respectively.

Three of 28 subjects in the plastazote group never had an ulcer during the period of study, so 25 are included in Figure 2. Five subjects who were initially ulcer free, developed ulcers, at least one because the new plastazote shoes did not fit well. Twelve of 40 subjects in the canvas shoe group never had an ulcer during the period of study, so 28 are included in Figure 1. None who were initially ulcer free developed ulcers.

The geometric mean size of ulcers over time for the two groups is shown in Figure 3, with confidence intervals for each value. There is a highly significant difference between the two groups at the end of the study. All ulcers in the canvas shoe group decreased in size (the majority of them healing completely), except in two instances. In one case, the only one in which a large ulcer showed no improvement over the year, a biopsy showed epidermal hyperplasia (requiring surgical excision); in the other case, a new ulcer appeared at the one-year follow-up, said to be due to inexpert trimming of dead skin by the person himself. 
Table 1. The characteristics of the two groups at the start of the study. Inversion was said to be present when part of the medial aspect of the sole was not in contact with the ground on standing or walking.

\begin{tabular}{lcc}
\hline & $\begin{array}{c}\text { Control group } \\
\text { plastazote shoes }\end{array}$ & $\begin{array}{c}\text { Experimental group } \\
\text { canvas shoes }\end{array}$ \\
\hline Total analysed & 28 & 40 \\
Age $<45$ & 16 & 21 \\
$\quad>45$ & 14 & 19 \\
M : F & $8: 20$ & $20: 20$ \\
Foot pathology: & & \\
Complete loss of protective sensation & 28 & 40 \\
Adsorbed toes (1 or more) & 28 & 40 \\
Ulceration & 20 & 28 \\
$\quad$ superficial ulcers (<5 mm deep) & 7 & 14 \\
$\quad$ deep ulcers (range: 5-15 mm deep) & 13 & 2 \\
Inversion of both feet & 4 & 9 \\
Inversion of one foot & 8 & 6 \\
Footdrop without inversion & 5 & 7 \\
Adsorbed forefoot: bilateral & 10 & 4 \\
$\quad$ unilateral & 7 & \\
& & \\
\end{tabular}

Deformed feet also did better with canvas shoes. Of the 11 subjects with inverted feet in this group, 9 had ulcers at the start (5 deep, 4 superficial) but only 4 had ulcers at one year. Of the 12 subjects with inverted feet in the plastazote group, 9 had ulcers at the start (6 deep, 3 superficial), but 11 had ulcers at the end of the study.

\section{DURABILITY}

In general, both types of shoes have a useful life of not more than 6 months if used on a daily basis. The plastazote insoles wore out in the majority of cases by 6 months while the soles and leather uppers remained in good condition. The canvas uppers were usually badly torn by 6 months, but the soles and MCR insoles of the canvas shoes remained in good condition.

We have attempted, in conjunction with the Canvas Shoe Factory, to strengthen the canvas uppers and the initial results are encouraging.

\section{ACCEPTABILITY}

Clients were asked how they themselves, their families and their neighbours liked the shoes and also how suitable the shoes were for their work. These questions were asked at each follow-up visit.

All the clients using canvas shoes found them excellent and more than $80 \%$ reported an excellent acceptance by family and neighbours, as well as suitability for work. One client, with a severly inverted foot in which the ulcer improved but did not heal, requested a pair of plastazote sandals for use at home and a pair of canvas shoes for work and activity away from home.

Approximately $60 \%$ of clients using plastazote sandals found them excellent, but full 


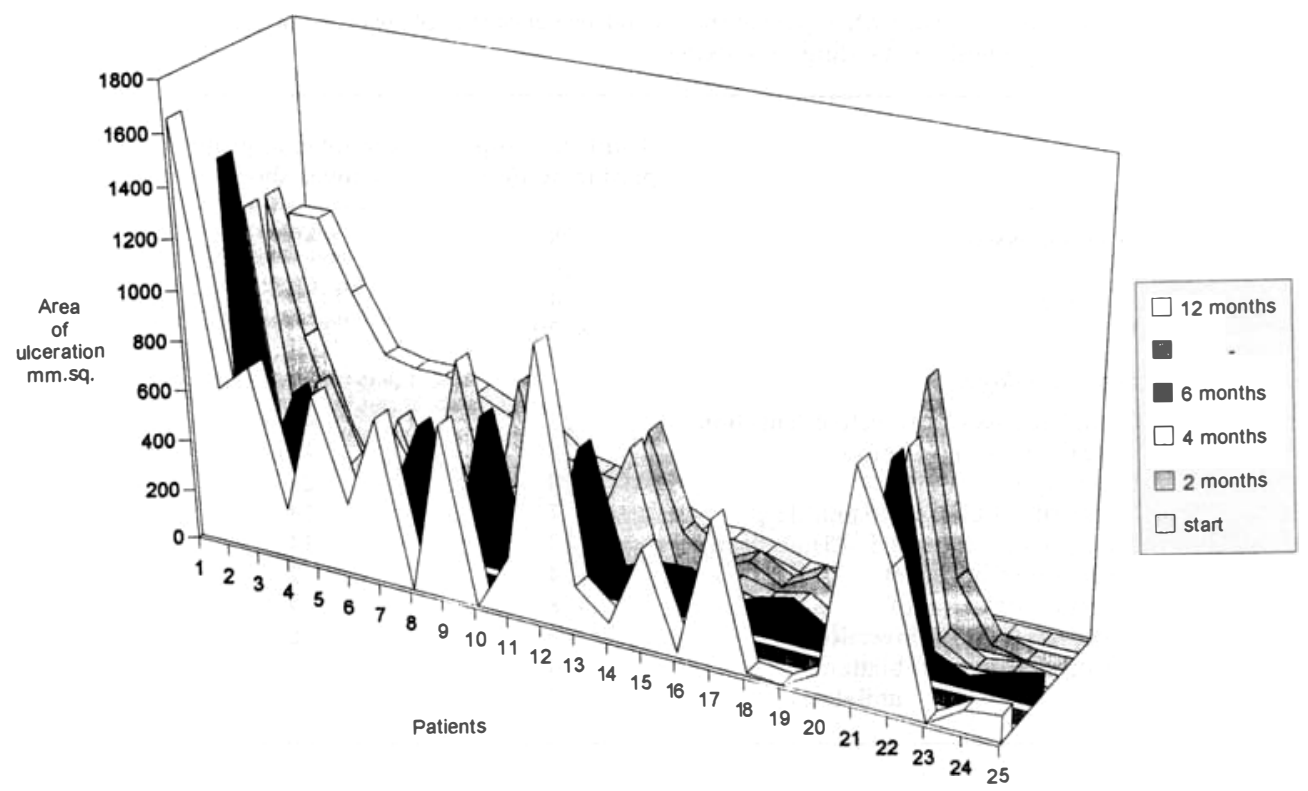

Figure 1. Ulcer size over time for the plastazote sandal group. The patients are placed in order of ulcer size at the start of the study and numbered 1-25. The area of ulceration for each patient at the start, is shown at the back of the diagram; moving towards the front, the area of ulceration at 2, 4, 6 and 12 months is seen for the same patients.

acceptance by family and neighbours was reported by no more than $20 \%$ at any time. Suitability for work was between $30 \%$ and $60 \%$.

\section{COST-EFFECTIVENESS ANALYSIS}

\section{Canvas shoes}

We have shown that 21 (75\%) of 28 subjects with deformed feet and chronic ulceration showed healing of the ulcers during a one-year period of regular use of canvas shoes.

The cost of these shoes is approximately US\$ 6.7 per pair and two pairs are required per person per year. For comparison MDT for MB patients costs about US\$ 15 per year.

Cost per ulcer healed: 16 ulcers were healed in the first 6 months and 6 more in the second 6 months. The first 16 ulcers were healed at an average cost of $28 \times 6 \cdot 7 / 16=11 \cdot 7$ US $\$$. The subsequent 6 were healed at a cost of $12 \times 13 \cdot 4 / 6=26 \cdot 8$ US $\$$. The average cost per ulcer healed was $28 \times 13 \cdot 4 / 22=17 \cdot 1$ US $\$$, over a one-year period.

Cost of ulcer prevention: 12 clients without ulcers but with anaesthetic and deformed feet, did not develop ulcers during the year; and 15 out of 16 clients with healed ulcers at 6 months remained ulcer-free for the second six months.

Ulcer prevention was therefore attempted for 40 subject/half-years at a cost of $40 \times 6 \cdot 7=268$ US $\$$. Ulcers were prevented in 39 of these half-year periods. The cost per ulcer prevented was therefore $268 / 39=6 \cdot 9 \mathrm{US} \$$. 


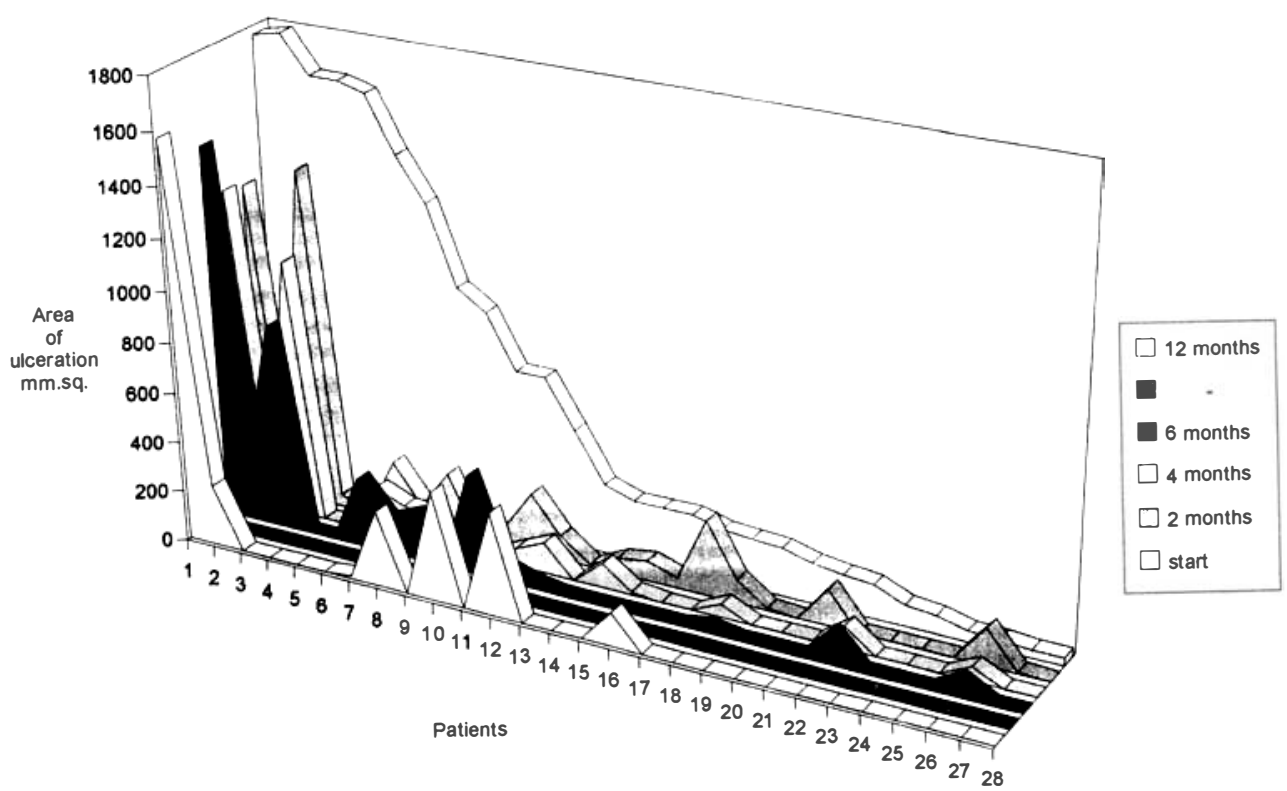

Figure 2. Ulcer size over time for the canvas shoe group. The patients are placed in order of ulcer size at the start of the study and numbered 1-28. The area of ulceration for each patient at the start, is shown at the back of the diagram; moving towards the front, the area of ulceration at 2, 4, 6 and 12 months is seen for the same patients.

\section{Plastazote sandals}

Plastazote sandals showed no overall benefit in healing and preventing ulceration. Eight of the group started without ulcers and 7 were ulcer-free at one year. Only 3 clients remained ulcer-free throughout.

\section{LABORATORY TESTING OF CANVAS SHOES}

Neuropathic plantar ulceration develops over areas of high pressure associated with deformity or joint limitation. Laboratory methods have been developed to show how effective different shoes are in reducing peak walking pressures. ${ }^{15}$ A sample of the Ethiopian Canvas Shoes (ECS) used in this study has been tested at the University of Liverpool, UK, and compared with a range of products available in different leprosy control programmes around the world. Pressure was measured at 10 points on the plantar surface of the foot during normal walking. Forty-one different shoes, sandals and insole materials were examined (including the ECS).

Table 2 compares the results for the ECS with the means and ranges for other samples and the results from walking barefoot. No shoes were consistantly at the low end of the range across all measurements, but the ECS was one of about 6 pairs to have consistently below average pressures. 
geometric mean ulcer size (sq $\mathrm{mm}$ )

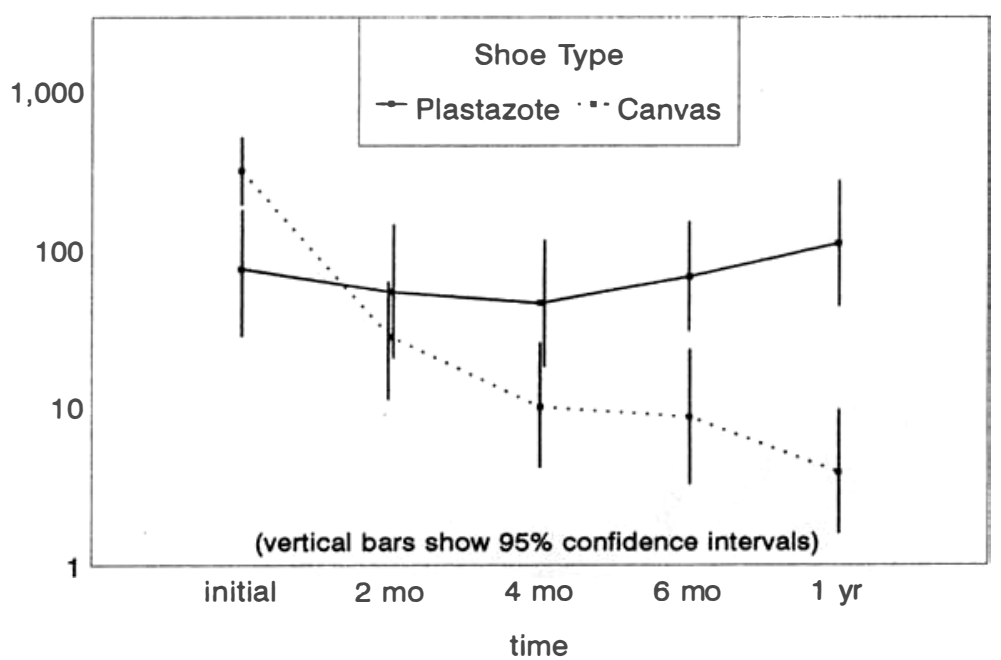

Figure 3. Geometric mean size of ulcers $\left(\mathrm{mm}^{2}\right)$ over time for 25 Ethiopian subjects with plastazote sandals and 28 subjects with canvas shoes.

\section{Discussion}

Previous studies have shown that it is possible to achieve high rates of ulcer-healing through various techniques, such as: good wound care and immobilization in a centre of excellence-94\% healed; ${ }^{4}$ podiatric orthoses- $57 \%$ healed; ${ }^{14}$ and the use of canvas shoes in China-84\% healed. ${ }^{11}$ The challenge for control programmes is to achieve and maintain ulcer-healing on a wide scale at the lowest possible cost and by a method straightforward enough to be applied through the general health services.

This study was carried out under field conditions in a rural part of Ethiopia, $250 \mathrm{~km}$ from Addis Ababa, where a large number of people affected by leprosy have settled. It

Table 2. The maximal force and peak pressures recorded at various points on the sole of a normal foot during walking, in the Ethiopian Canvas Shoe (ECS), in 40 other shoes or sole materials from other leprosy projects and barefoot.

\begin{tabular}{lrrrrr}
\hline & \multicolumn{5}{c}{ Mean and range for all 41 samples } \\
\cline { 2 - 6 } & ECS & mean & low & high & Barefoot \\
\hline Maximal force (Newtons) & & & & & \\
$\quad$ mean of readings for metatarsal heads & 50 & 75 & 44 & 100 & 93 \\
mean of readings for all 10 sites & 76 & 88 & 68 & 105 & 103 \\
$\quad$ reading for the heel & 394 & 394 & 290 & 461 & 472 \\
Peak pressure (N/cm sq) & & & & & \\
$\quad$ mean of readings for metatarsal heads & $16 \cdot 1$ & $16 \cdot 4$ & 9.2 & $22 \cdot 1$ & 25 \\
$\quad$ mean of readings for all 10 sites & $12 \cdot 8$ & $13 \cdot 3$ & $9 \cdot 5$ & $17 \cdot 3$ & $20 \cdot 7$ \\
reading for the heel & $19 \cdot 2$ & $19 \cdot 7$ & 13 & $27 \cdot 5$ & $31 \cdot 5$ \\
\hline
\end{tabular}


was prompted by the awareness that:

- People affected by leprosy have been taught how to carry out self-care, but a large number (which can only be guessed at) are unable to prevent chronic or recurrent ulceration of their anaesthetic feet, without appropriate protective footwear.

- The large numbers of former patients with anaesthetic feet (whether deformed or not) cannot be supplied with special footwear made in orthopaedic workshops. It is logistically impossible at present.

- Various commercial footwear manufacturers can make shoes which are protective for anaesthetic feet and are socially acceptable.

The study has shown that commercially produced canvas shoes are beneficial for clients who have deformed as well as anaesthetic feet. They are a cost-effective method of achieving ulcer-healing and or preventing new ulcers. Probably the most important aspect of the canvas shoes is their ready acceptance by both clients and community, while the specially made plastazote sandals immediately stigmatize the person as a leprosy case. It appears also that the canvas shoes are preferred for farm work and for walking on dusty and stoney grounds.

The study was unable to investigate why subjects with plastazote shoes showed no improvement overall. However, it is our impression that because of poor acceptability by the families and neighbours of clients, these shoes may not be worn on many occasions. However appropriate as a technical solution, plastazote sandals and even open MCR sandals, appear to be socially (and often functionally) unacceptable in Ethiopia. ${ }^{10}$ Conditions in different countries must be examined closely; for example, canvas shoes may not overcome problems such as working in paddy fields and not wearing shoes in the house, which are issues in India. ${ }^{6}$

At ALERT, we are trying to move away from the traditional monthly care clinic, where patients come for soaking, trimming and oiling, but then may do very little else for the rest of the month. We have recently started a pilot study of community-based selfcare, in which a group of clients living near each other meet weekly to assist each other in self-care and to discuss problems. A supervisor and foot-care specialist have been visiting monthly in the initial phase and early results are very promising.

We would therefore advocate a foot-care programme in which self-care is promoted and commercially available footwear is provided twice a year. In the long-run, most clients would only see a health worker or supervisor twice a year. People who still have an apparently simple ulcer after 1 year of using canvas shoes would require further investigation to discover the reason and may need referral for surgery. There may be epidermal hyperplasia, as in one of our subjects, or even a malignancy; surgical correction of deformities and reduction of pressure points may be indicated. This would also be the most appropriate stage for the provision of special footwear, after discussion between surgeon, orthotist and technician. It may be that two types of footwear, for use on different occasions, will be the best solution for some people with deformed feet.

While the annual cost of providing footwear is noted to be very similar to the cost of MDT for MB patients, the provision is not limited to the two years of MDT. Thus there are many more clients requiring footwear than are registered for MDT and they will require it for many years. It may be that some manufacturers can produce such shoes for a lower cost, and part of the cost can be recovered from clients, but this will still be an expensive programme, requiring further long-term commitment from donors. 


\section{Acknowledgments}

We thank Dr Diana Lockwood, Ms Heather Currie, Ms Catherine Benbow and Dr Roland Kazen for helpful comments; Dr Peter Byass for the statistical analysis; Dr Peter Byass for the statistical analysis; Mr Keith Linge for testing the shoes in the laboratory; Ato Gabre Yesus, Ato Sahelu and the Shashemane workshop for their cooperation; the ALERT field staff for their continuing care of patients and Wzt Almaz Mengesha for typing the manuscript.

ALERT is supported by ILEP members through NSL, the Netherlands Leprosy Relief Association.

\section{References}

${ }^{1}$ Kazen RO. Management of plantar ulcers-theory or practice? Lepr Rev 1993; 64: 188-89.

${ }^{2}$ Brand P. Insensitive feet. A practical handbook on foot problems in leprosy. 1981 The Leprosy Mission, London.

${ }^{3}$ Patil KM, Manoj R, Srinath MS, Oommen PK, Babu M, Malaviha GN. Analysis of static and dynamic foot pressure in leprosy patients. Abstract RE11. 14th International Leprosy Congress, Orlando, Florida. 1993.

4 Birke JA, Novick A, Patout CA, Coleman WC. Healing rates of plantar ulcers in leprosy and diabetes. Lepr Rev 1992; 63: 365-74.

5 Srinivasan H. Do we need trials of agents alleged to improve healing of plantar ulcers? Lepr Rev 1989; 60: 278-82.

6 Krishnamoorthy KV. Protective footwear for leprosy patients with sole sensory loss or ulceration of the foot. Lepr Rev 1994; 65: 400-2.

7 Srinivasan H. Deformities and disabilities - unfinished agenda in leprosy work. Lepr Rev 1995; 66: $193-200$.

8 Brand M. Pre-congress Workshops: Recommendations on rehabilitation. Lepr Rev 1988; 59: 304-5.

9 Becx-Bleumink M, Berhe D, Mannetje WT. The management of nerve damage in the leprosy control services. Lepr Rev 1990; 61: 1-11.

10 Becx-Bleumink M. Priorities for the future and prospects for leprosy control. Int J Lep 1993; 61: 82-101.

$11 \mathrm{Xu} \mathrm{S}$, Watson J. Comprehensive protection effects on leprosy sole ulcer and simple sole sensory loss. Abstract RE58. 14th International Leprosy Congress, Orlando, Florida. 1993.

$12 \mathrm{Xu} \mathrm{S}$, Watson J. Development and application of protective shoes for leprosy patients. Abstract RE59. 14th International Leprosy Congress, Orlando, Florida. 1993.

13 Kundin JI. A new way to size up a wound. Am J. Nursing 1989; (Feb.) 206-7.

14 Cross H, Sane S, Dey A, Kulkarni VN. The efficacy of podiatric orthoses as an adjunct to the treatment of plantar ulceration in leprosy. Lepr Rev 1995; 66: 144-57.

15 Birke JA, Foto JG, Deepak S, Watson J. Measurement of pressure walking in footwear used in leprosy. Lepr Rev 1994; 65: 262-71. 